13

\title{
Люминесцентный хемосенсор для детектирования паров диметиламина и аммиака
}

\author{
() А.С. Шишов, А.Г. Мирочник
}

Институт химии Дальневосточного отделения РАН, 690022 Владивосток, Россия

e-mail: mirochnik@ich.dvo.ru

Поступила в редакцию 16.08.2021 г.

В окончательной редакции 15.11.2021 г.

Принята к публикации 15.11.2021 г.

Исследовано взаимодействие трис-дибензоилметаната $\mathrm{Eu}(\mathrm{III})$ с парами диметиламина и аммиака. Обнаружено что при воздействии паров водных растворов аналитов на трис-дибензоилметанат $\mathrm{Eu}(\mathrm{III})$, импрегнированный в матрицу $\mathrm{SiO}_{2}$, наблюдается оптический отклик в виде возрастания интенсивности люминесценции $\mathrm{Eu}(\mathrm{III})$. Проанализированы изменения в спектрах люминесценции и возбуждения люминесценции данного сенсора как при тушащем действии паров воды, так и при сенсибилизирующем действии паров аналитов. Отмечены основные моменты, фиксируемые в спектрах возбуждения люминесценции, важные для понимания процессов, происходящих в ближнем окружении лантанидного центра. Люминесцентный хемосенсор перспективен для создания датчиков обнаружения аммиака и аминов при контроле безопасности пищевых продуктов и мониторинге окружающей среды.

Ключевые слова: европий(III), бета-дикетонаты, люминесценция, аммиак, диметиламин, сенсоры.

DOI: $10.21883 / \mathrm{OS} .2022 .02 .51999 .2644-21$

\section{Введение}

В настоящее время проводятся интенсивные исследования в области разработки полифункциональных материалов, обладающих оптическими хемосенсорными свойствами [1-4]. Анализ литературных данных показывает, что перспективными соединениями для получения оптических хемосенсоров являются соединения металлов [5,6], в особенности лантанидсодержащие комплексные соединения, обладающие люминесцентными свойствами [7-14].

К достоинствам люминесцентного сенсорного метода можно отнести малую зависимость сигнала от электрических, магнитных и радиационных помех, возможность надёжно герметизировать люминесцентный детекторанализатор, что позволяет регистрировать люминесцентный отклик в агрессивных средах или на значительных расстояниях. [7,15]

Молекулы воды являются эффективными тушителями люминесценции, поэтому удаление либо замещение координированных молекул воды, как правило, приводит к изменению интенсивности люминесценции и времени жизни возбуждённого состояния лантанидного иона [16,17]. Вытеснение связанной молекулы воды из лантаноидного центра является плодотворной стратегией для разработки хемосенсорных датчиков на основе лантаноидов.

Особый интерес для практического применения представляет разработка хемосенсорных систем для таких аналитов как аммиак и летучие амины. Аммиак в огромных объёмах применяется в химической промышленности (для производства удобрений, взрывчатых веществ, полимеров, азотной кислоты, соды). Жидкий аммиак используют в рефрижераторах в качестве хладагента, а также в химическом производстве в качестве растворителя. Аммиак токсичен, даже малые количества вещества губительно действуют на живые организмы [15]. В связи с интенсивным ростом жилищного строительства выявилась острая экологическая проблема, связанная с эмиссией аммиака и аминов из строительных и отделочных материалов и бетонных конструкций как на один из источников как кратковременного, так и длительного химического загрязнения воздушной среды жилых помещений. В результате загрязнения воздуха неуклонно снижается качество внутрижилищной среды и растет число людей с аллергическими и другими заболеваниями [18-20].

Синтетические амины производятся в количестве миллионов тонн ежегодно и широко применяются в сельском хозяйстве, фармацевтике и пищевой промышленности $[15,21]$. Биогенные и летучие амины также часто образуются при разложении аминокислот в метаболических процессах, и их аномально высокие концентрации могут указывать на порчу пищевых продуктов [22,23]

В продолжение наших работ по исследованию хемосенсорных свойств комплексных соединений $\mathrm{Eu}(\mathrm{III})$ [24-26] в настоящей работе представлены результаты исследования влияния паров воды, аммиака и диметиламина на люминесценцию хемосенсора $\mathrm{Eu}(\mathrm{Dbm})_{3} \cdot \mathrm{H}_{2} \mathrm{O}$, где $\mathrm{Dbm}$ - дибензоилметанат-анион. 


\section{Экспериментальная часть}

Трис-дибензоилметанат $\mathrm{Eu}(\mathrm{III})$ синтезирован по методике, описанной в [27]. Комплексное соединение получено взаимодействием $\mathrm{Eu}\left(\mathrm{NO}_{3}\right)_{3} \cdot 6 \mathrm{H}_{2} \mathrm{O}$ и дибензоилметана с мольным соотношением 1:3, смешением растворов чистых веществ в абсолютизированном этаноле при нагревании. В дальнейшем производилась нейтрализация итогового раствора (до рН 8) добавлением по каплям этанольного раствора аммиака. Полученный жёлтый осадок отфильтровали, промыли этанолом, высушили на воздухе.

В качестве матрицы для импрегнирования комплекса $\mathrm{Eu}(\mathrm{III})$ были использованы пластины для тонкослойной хроматографии ПТСХ-АФ-А фирмы Sorbfil. Образцы получали нанесением на данную матрицу раствора трисдибензоилметаната $\mathrm{Eu}(\mathrm{III})$ в ацетоне $\left(C=1 \cdot 10^{-4} \mathrm{M}\right)$ и выдерживанием в сухой атмосфере в течение $30 \mathrm{~min}$ до полного испарения растворителя. Образцы хранились тщательно упакованными в полиэтилен в эксикаторе над $\mathrm{SiO}_{2}$.

Спектры люминесценции и возбуждения люминесценции образцов регистрировали с помощью спектрофлуориметра RF-5301 (Shimadzu). Для обнаружения люминесцентного отклика образцы помещали в оптическую кювету с крышкой (толщина кюветы $1 \mathrm{~cm}$, высота $4 \mathrm{~cm}$ ), в которую добавляли 1 каплю $(0.05 \mathrm{ml})$ водного раствора аммиака или диметиламина для создания определенного давления насыщенных паров; кювета термостатировалась при $20^{\circ} \mathrm{C}$, баростатирование отсутствовало.

\section{Результаты и обсуждение}

О сильном тушащем действии паров воды на люминесценцию свидетельствует данные рис. 1, из которых видно, что при воздействии паров воды наблюдается практически полное тушение люминесценции (интенсивность люминесценции модельного образца хемосенсора уменьшается в течение $10 \min$ в 8 раз).

Следует отметить, что после просушки образца хемосенсора интенсивность люминесценции полностью восстанавливается, что подтверждено в работах [24,25].

В отличие от паров воды при воздействии паров водных растворов аммиака и диметиламина на хемосенсор регистрируется увеличение интенсивности люминесценции, т.е. несмотря на присутствие паров воды, сами аммиак и диметиламин производят сенсибилизирующее действие (3D-коллаж на рис. 2, где $a-$ диметиламин и $b$ - аммиак). Из данных рис. 2, где представлена эволюция спектров возбуждения люминесценции в зависимости от времени, регистрируется сложная последовательность преобразования огибающих спектров.

Рассмотрим более подробно воздействие паров водного раствора диметиламина на образец хемосенсора. Из данных рис. 2, $a$ и рис. 3 видно, что в начальный период воздействия аналита наблюдается быстрое увеличение

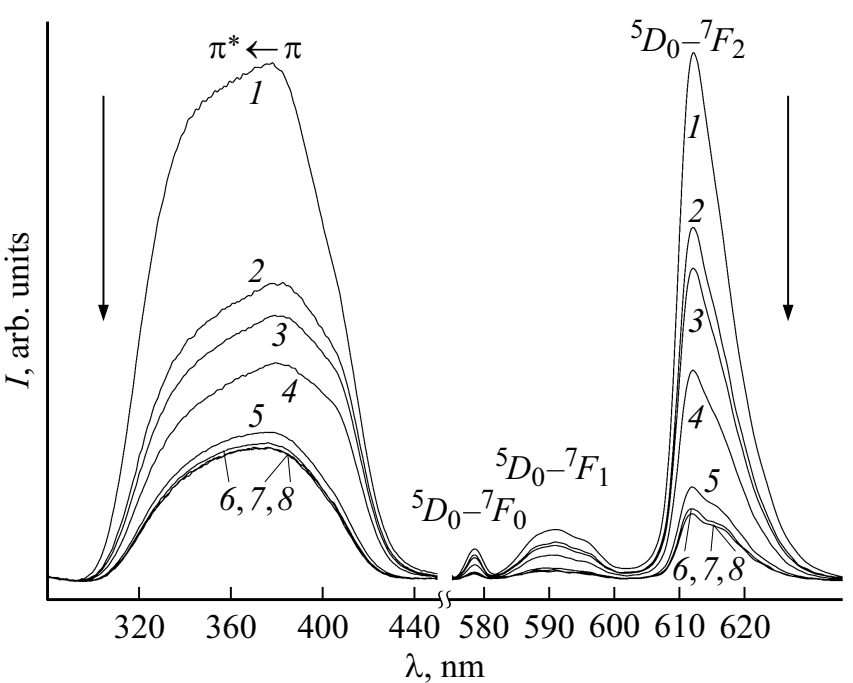

Pис. 1. Спектры возбуждения люминесценции и люминесценции хемосенсора при воздействии паров воды. Спектры люминесценции: $1-0,2-26,3-38,4-86,5-$ $326,6-602,7-900,8-1800$ s. Спектры возбуждения люминесценции: $1-0,2-30,3-56,4-108,5-342$, $6-576,7-888,8-1770 \mathrm{~s}$.

интенсивности люминесценции без перестройки штарковских компонент спектра.

Это свидетельствует о том, что сенсибилизирующее действие аналита на модельный хемосенсор $\mathrm{Eu}(\mathrm{Dbm})_{3} \cdot \mathrm{H}_{2} \mathrm{O}$ в начальный период происходит без явной перестройки внутренней сферы $\mathrm{Eu}(\mathrm{III})$ и проявляется в усилении антенного эффекта за счёт увеличения эффективности переноса энергии лиганд-металл [7]. Такое обратимое действие характерно для многих летучих аминов и аммиака даже при минимальных концентрациях аналита ( 5 ppbv), как это показано ранее [24,25].

При дальнейшем воздействии паров диметиламина наблюдается кратковременное понижение интенсивности люминесценции с изменением штарковской структуры спектров люминесценции и заметное изменение структуры спектров возбуждения люминесценции (рис. 2,a). Это может свидетельствовать о явной перестройке внутренней координационной сферы $\mathrm{Eu}(\mathrm{III})$. Уменьшение интенсивности люминесценции в этот период в основном вызвано тушащим действием молекул воды.

В дальнейшем, с течением времени наблюдается рост интенсивности люминесценции с выходом на плато. Это свидетельствует о выходе на плато тушащего действия паров воды и превалировании процессов сенсибилизации люминесценции при действии паров диметиламина. О перестройке внутренней координационной сферы $\mathrm{Eu}(\mathrm{III})$ и изменении симметрии кристаллического поля ближайшего окружения европия свидетельствует изменение штарковской структуры переходов ${ }^{5} D_{0}-{ }^{7} F_{0}$, ${ }^{5} D_{0}-{ }^{7} F_{1}$ и ${ }^{5} D_{0}-{ }^{7} F_{2}$ (рис. 3 , вставки). Помимо изменения штарковской структуры для перехода ${ }^{5} D_{0}-{ }^{7} F_{2}$ при воздействии аналита характерен отчётливый батохромный сдвиг полосы люминесценции $(\sim 1 \mathrm{~nm})$. 


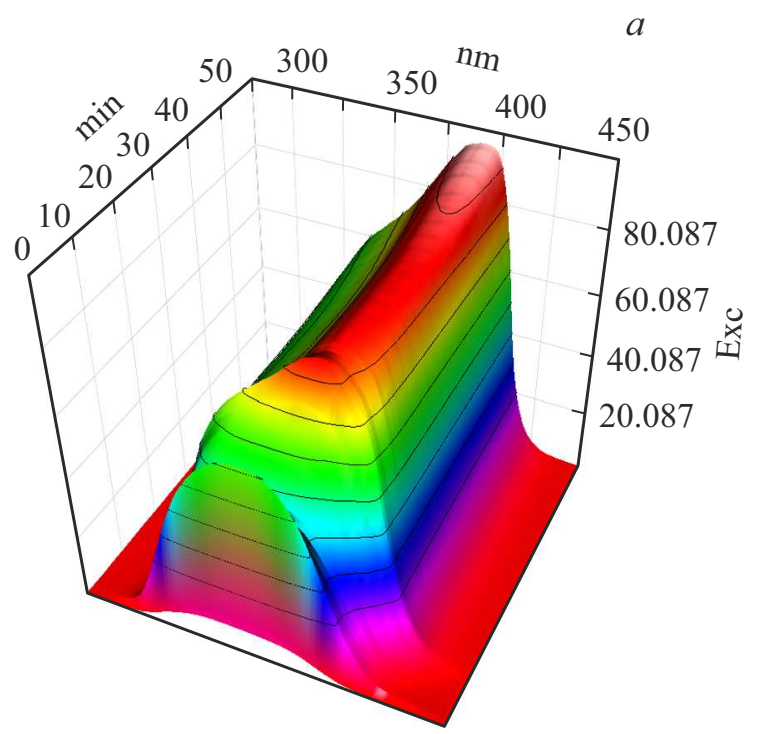

$b$

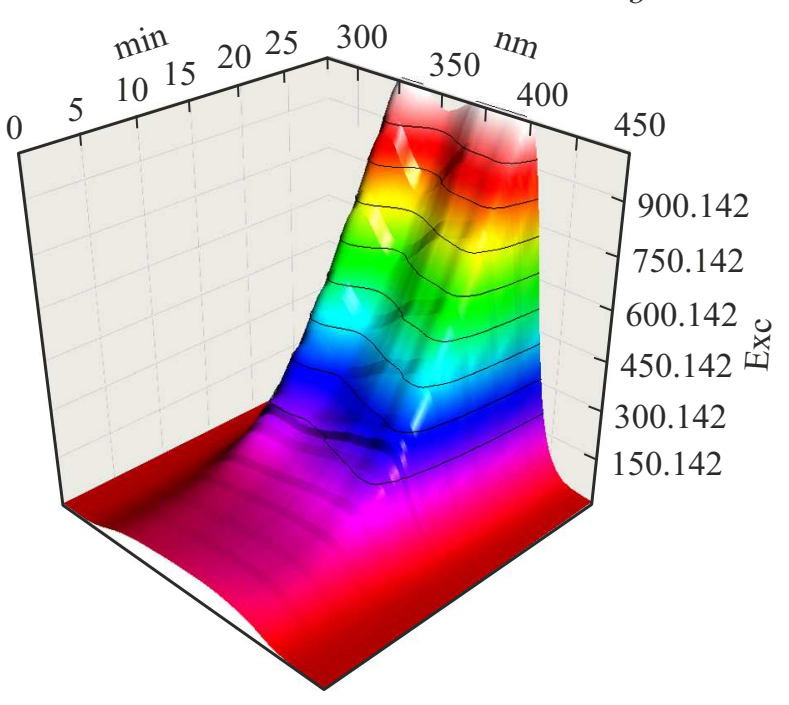

Рис. 2. 3D-спектры возбуждения люминесценции хемосенсора при воздействии паров диметиламина $(a)$ и аммиака $(b)$. По оси ординат отложена интенсивность в rel. units, по другим осям - время в min и длина волны в $\mathrm{nm}$.

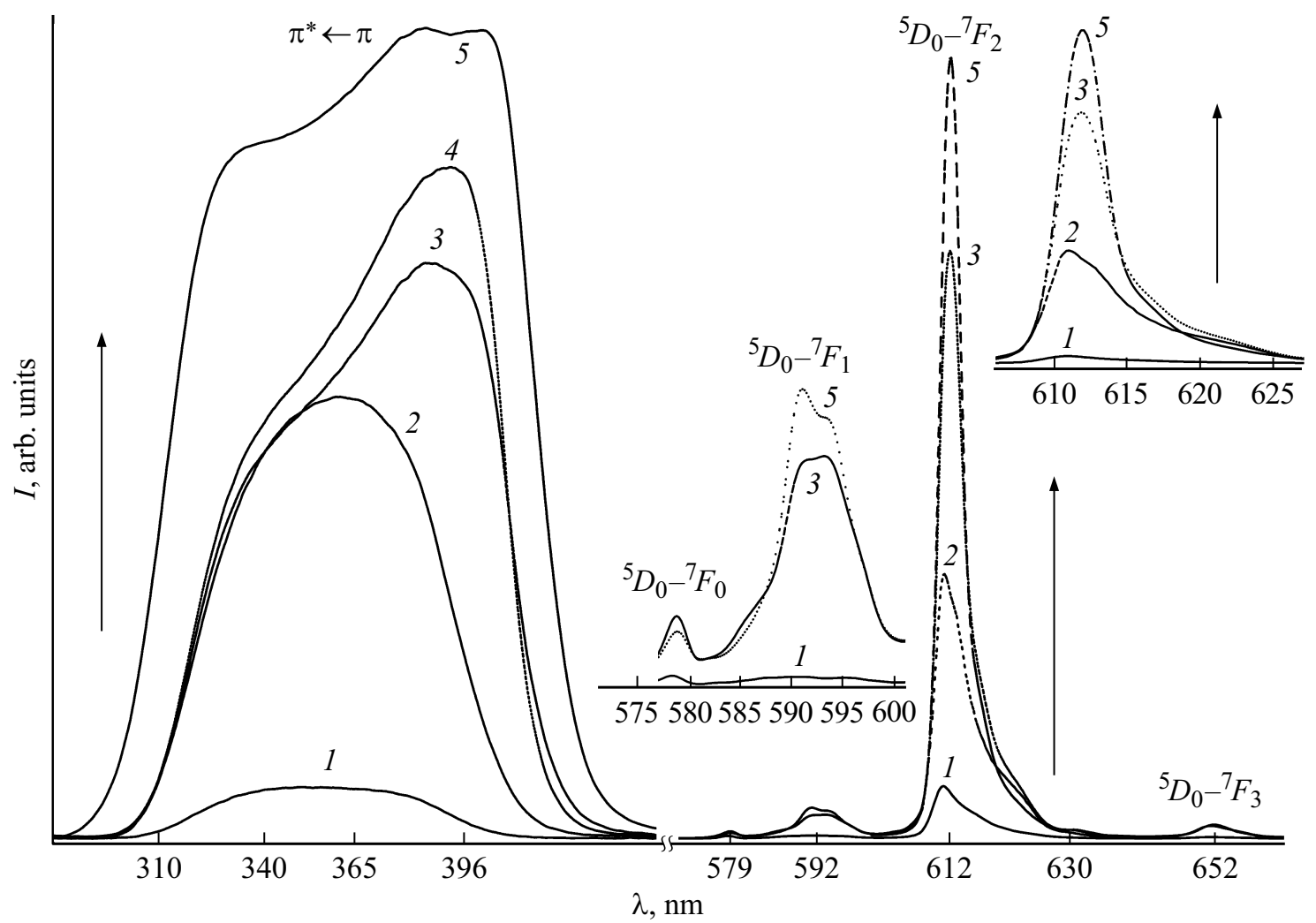

Рис. 3. Спектры возбуждения люминесценции и люминесценции хемосенсора при воздействии паров диметиламина. Спектры люминесценции: $1-0 \mathrm{~s}, 2-20 \mathrm{~s}, 3-17 \mathrm{~min}, 5-143 \mathrm{~min}$. Спектры возбуждения люминесценции: $1-0 \mathrm{~s}, 2-30 \mathrm{~s}, 3-$ $18 \mathrm{~min}, 4-71 \mathrm{~min}, 5-145 \mathrm{~min}$. На вставках показано изменение штарковской структуры переходов ${ }^{5} D_{0}-{ }^{7} F_{j}(j=0,1,2)$.

Рассмотрим воздействие паров водного раствора аммиака на модельный образец хемосенсора. Из данных рис. $2, b$, где представлена эволюция $3 D$-спектров возбуждения люминесценции в зависимости от времени, видно, что при воздействии аммиака регистрируется сложная последовательность преобразования огибающих спектров.

На рис. 4 представлена эволюция спектров возбуждения люминесценции и люминесценции хемосенсора при воздействии аммиака. С течением времени наблюдает- 
ся последовательный рост интенсивности спектральных полос: после $15 \mathrm{~min}$ воздействия аналита интенсивность люминесценции электродипольного перехода ${ }^{5} D_{0}-{ }^{7} F_{2}$ возрастает в 10 раз. При этом наблюдаются радикальные изменения структуры полосы возбуждения люминесценции: с течением времени при воздействии аммиака широкая диффузная полоса $(355 \mathrm{~nm})$ преобразуется в отчётливый триплет (330, 380 и $395 \mathrm{~nm})$. Эти данные свидетельствуют о том, что при воздействии молекул аммиака происходит перестройка внутренней координационной сферы $\mathrm{Eu}(\mathrm{III})$ и модуляция антенного эффекта, т.е. изменение эффективности переноса энергии электронного возбуждения лиганд-металл.

При дальнейшем воздействии аммиака на модельный хемосенсор (через $84 \mathrm{~min}$ ) происходит трансформация спектров возбуждения люминесценции: расщепление полосы $355 \mathrm{~nm}$ на дублет с максимумами 322 и $395 \mathrm{~nm}$ (рис. 5). Возрастание и выход на плато интенсивности люминесценции свидетельствует о выходе на плато тушащего действия паров воды и превалировании процессов сенсибилизации люминесценции при действии паров аммиака.

Важной особенностью модельного хемосенсора $\mathrm{Eu}(\mathrm{Dbm})_{3} \cdot \mathrm{H}_{2} \mathrm{O}$ является обратимость взаимодействия субстрат-аналит: при продувке и просушке образца хемосенсора интенсивность люминесценции восстанавливается (рис. 4, линия 7), что подтверждено в работах $[24,25]$.

Полученные данные свидетельствуют о том, что при исследовании хемосенсорных свойств лантанидных комплексов помимо анализа полос люминесценции дополнительный анализ спектров возбуждения люминесценции является эффективным методом исследования взаимодействия субстрат-аналит. Следует подчеркнуть, что

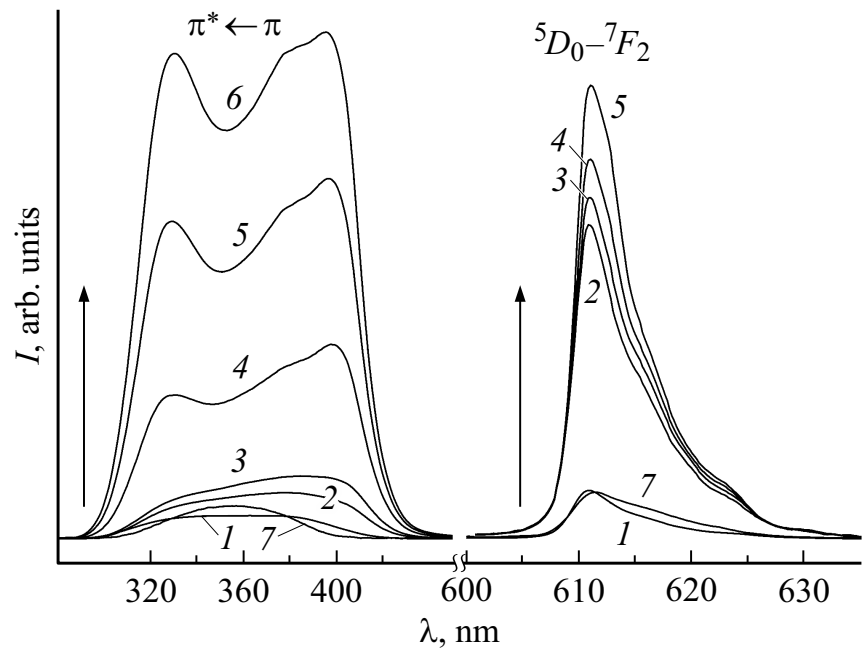

Рис. 4. Спектры возбуждения люминесценции и люминесценции хемосенсора при воздействии паров аммиака. Спектры люминесценции: $1-0,2-20,3-65,4-545,5-880 \mathrm{~s}$. Спектры возбуждения люминесценции: $1-0,2-30,3-$ $310,4-980 \mathrm{~s}, 5-21 \mathrm{~min}, 6-25 \mathrm{~min}, 7-$ после продувки камеры и просушки образца.

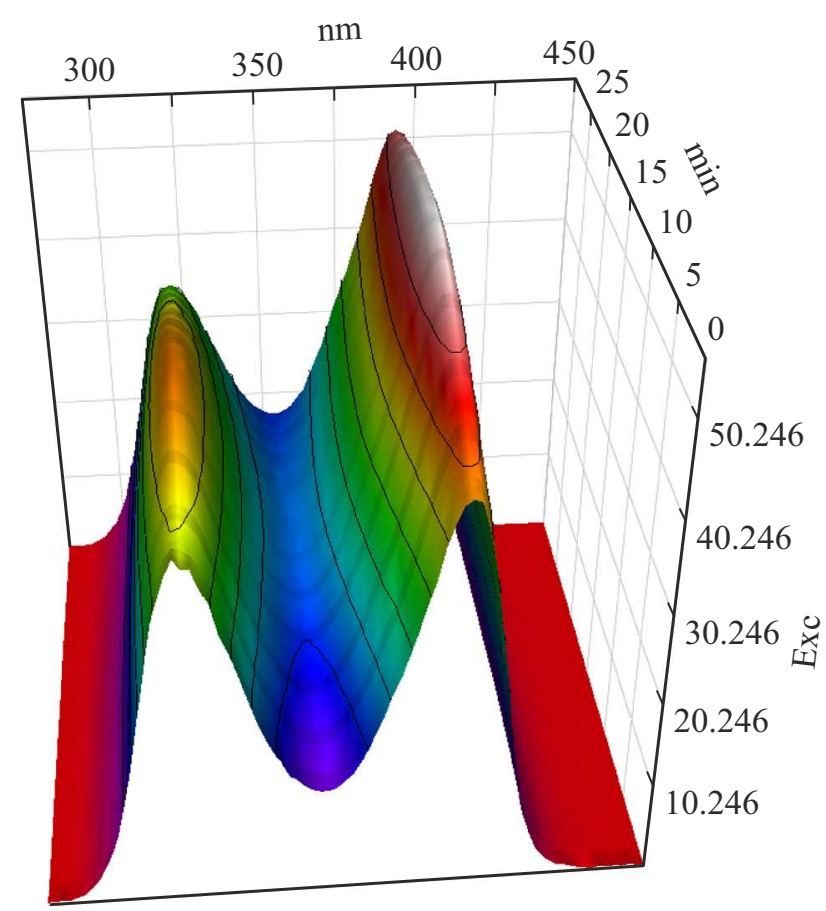

Рис. 5. 3D-спектр возбуждения люминесценции хемосенсора при воздействии паров аммиака. По оси ординат отложена интенсивность в rel. units, по другим осям - время в min и длина волны в $\mathrm{nm}$.

характерной особенностью эволюции спектров возбуждения люминесценции является селективность по отношению к аналиту. Действительно, анализ экспериментальных данных убедительно свидетельствует о своеобразии эволюции спектров возбуждения люминесценции: при воздействии паров воды происходит монотонное уменьшение интенсивности полос без изменения контура полосы. С другой стороны, при воздействии аммиака и диметиламина происходит возрастание интенсивности полос, и контуры полос трансформируется в дублет и триплет с различным соотношением интенсивностей компонент. Подобная селективность эволюции спектров возбуждения люминесценции может быть полезна при анализе экспериментальных данных при исследовании хемосенсорных свойств лантанидных комплексов.

\section{Заключение}

Исследовано взаимодействие трис-дибензоилметаната $\mathrm{Eu}(\mathrm{III})$ с парами диметиламина и аммиака. Обнаружено что при воздействии паров водных растворов аналитов на трис-дибензоилметанат $\mathrm{Eu}(\mathrm{III})$, импрегнированный в матрицу $\mathrm{SiO}_{2}$, наблюдается оптический отклик в виде возрастания интенсивности люминесценции $\mathrm{Eu}(\mathrm{III})$. Проанализированы изменения в спектрах люминесценции и возбуждения люминесценции данного сенсора как при тушащем действии паров воды, так и при сенсибилизирующем действии паров аналитов. Отмечены основные моменты, фиксируемые в спектрах возбуждения 
люминесценции, важные для понимания процессов, происходящих в ближнем окружении лантанидного центра.

Полученные данные свидетельствуют о том, что при исследовании хемосенсорных свойств лантанидных комплексов помимо анализа полос люминесценции дополнительный анализ спектров возбуждения люминесценции является эффективным методом исследования взаимодействия субстрат-аналит.

Люминесцентный хемосенсор перспективен для создания датчиков обнаружения аммиака и аминов при контроле безопасности пищевых продуктов и мониторинге окружающей среды.

\section{Финансирование работы}

Работа выполнена при финансовой поддержке Российского фонда фундаментальных исследований, проект № 19-03-00409.

\section{Конфликт интересов}

Авторы заявляют, что у них нет конфликта интересов.

\section{Список литературы}

[1] M. Venkateswarulu, P. Gaur, R.R. Koner. Sensors and Actuators B: Chem., 210, 144-148 (2015).

DOI: $10.1016 / j . s n b .2014 .12 .082$

[2] T.W. Bell, N.M. Next. Optical Biosensors: Present and Future, ed. by F.S. Ligler and C.A. Rowe Taitt (Elsevier Science B.V., 2002), ch. 11, p. 331-368. DOI: 10.1016/B978044450974-1/50011-2

[3] A.P. Silva, D.B. Fox, A.J.M. Huxley, T.S. Moody. Coord. Chem. Rev., 205 (1), 41-57 (2000). DOI: 10.1016/S00108545(00)00238-1

[4] H.S. Mader, O.S. Wolfbeis. Anal Chem., 82 (12), 5002-5004 (2010). DOI: 10.1021/ac1007283

[5] M. Myers, A. Podolska, C. Heath, M.V. Baker, B. Pejcic. Analyt. Chim. Acta., 819, 78-81 (2014). DOI: $10.1016 /$ j.aca.2014.02.004

[6] I.A. Ibarra, T.W. Hesterberg, J.S. Chang, J.W. Yoon, B.J. Holliday, S.M. Humphrey. Chem. Commun., 49 (64), 7156-7158 (2013). DOI: 10.1039/C3CC44575E

[7] M.L. Aulsebrook, B. Graham, M.R. Grace, K.L. Tuck. Coord. Chem. Rev., 375, 191-220 (2018). DOI: $10.1016 /$ j.ccr.2017.11.018

[8] Y. Zhang, B. Li, H. Ma, L. Zhang, Y. Zheng. Biosensors and Bioelectronics, 85, 287-293 (2016). DOI: 10.1016/j.bios.2016.05.020

[9] H. Weng, B. Yan. Sensors and Actuators B: Chem., 228, 702708 (2016). DOI: 10.1016/j.snb.2016.01.101

[10] P.Y. Du, S.Y. Liao, W. Gu, X. Liu. J. Solid State Chem., 244, 31-34 (2016). DOI: 10.1016/j.jssc.2016.09.011

[11] X. Shen, B. Yan. J. Colloid Interface Science, 451, 63-68 (2015). DOI: 10.1016/j.jcis.2015.03.039

[12] S. Roy, A. Chakraborty, T.K. Maji. Coord. Chem. Reviews, 273-274, 139-164 (2014). DOI: 10.1016/j.ccr.2014.03.035

[13] B.V. Harbuzaru, A. Corma, F. Rey, P. Atienzar, J.L. Jordá, H. García, D. Ananias, L.D. Carlos, J. Rocha. Angew. Chem. Int. Ed. Engl., 47 (6), 1080-1083 (2008).

DOI: $10.1002 /$ anie.200704702
[14] C. Yang, J. Luo, J. Ma, D. Zhu, L. Miao, Y. Zhang, L. Liang, M. Lu. Synth. Met., 162 (13-14), 1097-1106 (2012). DOI: 10.1016/j.synthmet.2012.05.005

[15] B. Timmer, W. Olthuis, A. van den Berg. Sens. Actuators. B, 107 (2), 666-677 (2005). DOI: 10.1016/j.snb.2004.11.054

[16] S.J. Butler, D. Parker. Chem. Soc. Rev., 42 (4), 1652-1666 (2013). DOI: 10.1039/c2cs35144g

[17] V.L. Ermolaev, E.B. Sveshnikova, E.N. Bodunov. PhysicsUspekhi., 39 (3), 261-282 (1996). DOI: 10.1070/PU1996v039n03ABEH000137

[18] Е.Е. Румянцева. Экологическая безопасность строительных материалов, конструкций и изделий (Университетская книга, Москва, 2011).

[19] С.П. Сивков. Технологии бетона, 5-6, 15-17 (2012).

[20] Z. Bai, Y. Dong, Z. Wang, T. Zhu. Environ. Int., 32 (3), 303 311 (2006). DOI: 10.1016/j.envint.2005.06.002

[21] S.A. Lawrence. Amines: Synthesis, Properties, and Applications (Cambridge University Press, Cambridge, 2004). DOI: 10.1021/op0501390

[22] A. Pacquit, J. Frisby, D. Diamond, K.T. Lau, A. Farrell, B. Quilty, D. Diamond. Food Chem., 102 (2), 466-470 (2007). DOI: 10.1016/j.foodchem.2006.05.052

[23] G. Meng, L. Shiwu, L. Yuhan, G. Yi, L. Xia, W. Luochao, Q. Anjun, T. Ben Zhong. ACS Sens., 1 (2), 179-184 (2016). DOI: $10.1021 /$ acssensors.5b00182

[24] Н.В. Петроченкова, А.Г. Мирочник, А.С. Шишов, А.А. Сергеев, С.С. Вознесенский. Журн. физ. хим., 88 (1), 126 (2014). [N.V. Petrochenkova, A.G. Mirochnik, A.S. Shishov, A.A. Sergeev, S.S. Voznesenskii. Russ. J. Phys. Chem., 88, 158-162 (2014). DOI: 10.1134/S0036024414010191]

[25] A.G. Mirochnik, N.V. Petrochenkova, A.S. Shishov, B.V. Bukvetskii, T.B. Emelina, A.A. Sergeev, S.S. Voznesenskii. Spectrochim. Acta. A, 155, 111-115 (2016).

DOI: 10.1016/j.saa.2015.11.004

[26] S.S. Voznesenskiy, A.A. Sergeev, A.G. Mirochnik, A.A. Leonov, N.V. Petrochenkova, A.S. Shishov, T.B. Emelina, Yu.N. Kulchin. Sensors and Actuators. B: Chem., 246, 4652 (2017). DOI: 10.1016/j.snb.2017.02.034

[27] В.А. Батырева, В.В. Козик, В.В. Серебренников, Г.М. Якунина. Синтезы соединений редкоземельных элементов, под ред. В.В. Серебренникова (Изд-во Томского ун-та, Томск, 1983), ч. 1, с. 133. 